\title{
Correction to: The Effect of Geological Heterogeneity and Groundwater Table Depth on the Hydraulic Performance of Stormwater Infiltration Facilities
}

\section{Andrea D'Aniello ${ }^{1} \cdot$ Luigi Cimorelli $^{1} \cdot$ Luca Cozzolino $^{2} \cdot$ Domenico Pianese $^{1}$}

Published online: 19 November 2019

(C) Springer Nature B.V. 2019

\section{Correction to: Water Resour Manag \\ https://doi.org/10.1007/s11269-018-2172-5}

The original version of this article unfortunately contains mistakes introduced during the publishing process. The mistakes and corrections are described in the following list, the main error lies in Table 3, page 1152:

1) The values of horizontal and vertical correlation length are inverted. Therefore, the correct values should be:

- Horizontal Correlation Length $=1.5 \mathrm{~m}$;

- Vertical Correlation Length $=5 \mathrm{~m}$.

Publisher's Note Springer Nature remains neutral with regard to jurisdictional claims in published maps and institutional affiliations.

The online version of the original article can be found at https://doi.org/10.1007/s11269-018-2172-5

Andrea D'Aniello

andrea.daniello@unina.it

1 Department of Civil, Architectural and Environmental Engineering, University of Naples Federico II, via Claudio 21, 80125 Napoli, Italy

2 Department of Engineering, Centro Direzionale di Napoli, Parthenope University of Naples, Isola C4, 80143 Napoli, Italy 